\title{
The effect of Tai Chi on the pulmonary rehabilitation of chronic obstructive pulmonary disease: a systematic review and meta-analysis
}

\author{
Xin Liu ${ }^{1,2 \#}$, Cuiping $\mathrm{Fu}^{3 \#}$, Weiping $\mathrm{Hu}^{2 \#}$, Shengyu $\mathrm{Hao}^{2}$, Liang $\mathrm{Xie}^{2}, \mathrm{Xu} \mathrm{Wu}^{2}$, Jihong Wang ${ }^{1}$, Zilong Liu ${ }^{2}$, \\ Qunying $\mathrm{Lin}^{4}$, Shanqun $\mathrm{Li}^{2}$
}

${ }^{1}$ Department of Pulmonary and Critical Care Medicine, Fujian Medical University Teaching Hospital, Fujian Provincial Geriatric Hospital, Fujian Provincial Hospital North Branch, Fuzhou, China; ${ }^{2}$ Department of Pulmonary Medicine, Zhongshan Hospital, Fudan University, Shanghai, China; ${ }^{3}$ Department of Pulmonary Medicine, the First Hospital Affiliated to Soochow University, Suzhou, China; ${ }^{4}$ Department of Respiratory Medicine, Affiliated Hospital of Putian University, Putian, China

Contributions: (I) Conception and design: X Liu; (II) Administrative support: Q Lin, S Li; (III) Provision of study materials or patients: None; (IV) Collection and assembly of data: X Liu, C Fu; (V) Data analysis and interpretation: All authors; (VI) Manuscript writing: All authors; (VII) Final approval of manuscript: All authors.

\#These authors contributed equally to this work.

Correspondence to: Shanqun Li, PhD. Department of Pulmonary Medicine, Zhongshan Hospital, Fudan University, 180 Fenglin Rd., Shanghai 200032, China. Email: li.shanqun@zs-hospital.sh.cn; Qunying Lin, MSc. Department of Respiratory Medicine, Affiliated Hospital of Putian University, 181 Meiyuan east Rd., Putian 351100, China. Email: linqyin@126.com.

Background: The effectiveness of Tai Chi for chronic obstructive pulmonary disease (COPD) so far is unclear. The present systematic review aimed to determine the influence of Tai Chi among people with COPD.

Methods: We searched six electronic databases for relevant studies in September, 2019. The methods of standard meta-analysis were used for identifying relevant studies, quality appraisal, and synthesis. The primary outcomes were six-minute walking distance (6MWD), percentage predicted forced expiratory flow volume in the first second (\% PredFEV $\mathrm{F}_{1}$ ), and St. George's Respiratory Questionnaire (SGRQ) score.

Results: A total of 23 studies including 1663 participants were included in the meta-analysis. The pooled data showed that the Tai Chi group was associated with a significant improvement in 6MWD [mean difference (MD) 40.83 m, 95\% CI: 32.47 to 49.19], \% PredFEV 1 (MD 1.67\%, 95\% CI: 0.41 to 2.93), SGRQ score (MD -6.57, 95\% CI: -10.17 to -2.98), and Chronic Respiratory Disease Questionnaire (CRQ) (MD 1.60, 95\% CI: 0.89 to 2.30) relative to the blank control population. When compared with breathing exercises, the 6MWD was significantly enhanced with Tai Chi (MD 14.15 m, 95\% CI: 3.76 to 24.53). Finally, when compared with breathing and walking exercises, Tai Chi was associated with a significant improvement in 6MWD (MD $7.68 \mathrm{~m}, 95 \% \mathrm{CI}: 2.28$ to $13.09 \mathrm{~m}$ ) and SGRQ score (MD -6.31, 95\% CI: -9.13 to -1.48$)$.

Conclusions: Tai Chi may have the potential to reduce dyspnoea, enhance exercise capacity, and improve the quality of life in COPD patients. People with COPD may obtain benefit from practicing Tai Chi.

Keywords: Tai Chi; pulmonary disease; chronic obstructive; dyspnea; exercise tolerance

Submitted Apr 13, 2020. Accepted for publication Jan 08, 2021.

doi: 10.21037/apm-20-940

View this article at: http://dx.doi.org/10.21037/apm-20-940 


\section{Introduction}

People with chronic obstructive pulmonary disease (COPD) experience persistent respiratory symptoms including dyspnea and decreased quality of life. The 2013 Global Initiative for Chronic Obstructive Lung Disease (GOLD) guidelines suggest all patients with stable COPD would benefit from physical activity (PA) (1). Various forms of pulmonary rehabilitation have been adopted widely. Tai Chi as a form of traditional Chinese meditative exercise arose in ancient China, exhibiting components such as the movements of Qigong, Yoga practices, and breathing control. It focuses the mind to control deep breathing, balance, and rhythmic circular motions. The majority of studies suggest the exercise intensity of Tai Chi to be about 3.5 METs (low-moderate intensity aerobic activity) $(2,3)$. The exercise does not require training equipment or a specific venue. In recent years, Tai Chi has been performed to treat chronic conditions widely. Whether and how people with COPD benefit from this exercise have become the focus of researchers' attention. With the increase in relevant literature, the effectiveness of Tai Chi for patients with COPD has been investigated in the past decade with conflicting results. A meta-analysis by $\mathrm{Wu}$ et al. reported that meditative movements (Tai Chi, yoga, and qigong) may have the potential to enhance lung function and PA in COPD patients (4). Elsewhere, a clinical trial by Zhang et al. indicated that Tai Chi had no impact on improving pulmonary function (5). Herein, we performed a metaanalysis to determine whether people with COPD benefit from Tai Chi as compared with breathing and walking exercises, considering dyspnoea, exercise capacity, and health-related quality of life. We present the following article in accordance with the PRISMA Reporting checklist (available at http://dx.doi.org/10.21037/apm-20-940).

\section{Methods}

We followed the Preferred Reporting Items for Systematic Reviews and Meta-Analyses statement (PRISMA) as standard guidelines (6). The study population, intervention, control, and outcomes as important factors were extracted from the retrieved studies.

\section{Literature search}

The PubMed (http://www.ncbi.nlm.nih.gov/pubmed), Cochrane Central Register for Controlled Trials (https:// www.cochranelibrary.com/central), Embase (http://ovidsp. tx.ovid.com), China National Knowledge Infrastructure (http://www.cnki.net/), China Biology Medicine (http:// sinomed.imicams.ac.cn/), and Wangfang Data (http:// www.wanfangdata.com.cn/) electronic databases were searched for studies to include in the present meta-analysis (up to September 2019), using the terms "Tai ji" OR "Tai Chi" OR "Tai Chi Chuan" AND "chronic obstructive pulmonary disease" OR "COPD" OR "chronic obstructive lung disease" OR "chronic obstructive airway disease" OR "emphysema" OR "chronic airflow limitation" OR "chronic airway obstruction". The abbreviations of these terms were also used. No language or publication year restrictions were applied. The reference lists of related articles were examined manually to identify potential studies that could have been missed by the initial electronic searches.

\section{Study criteria and selection}

The following inclusion criteria defined eligible studies for this meta-analysis: (I) randomized controlled trials (RCTs), (II) covered subjects diagnosed with COPD according to the GOLD guideline, (III) used any form of Tai Chi as an intervention and involved a control group or used another treatment or another exercise as a comparison, (IV) reported related outcomes for cases and controls, including lung function, exercise capacity, and health-related quality of life.

\section{Data extraction}

Two researchers (X Liu and $\mathrm{C} \mathrm{Fu}$ ) extracted the data from each study independently. Any disagreements between the two authors were resolved by consensus or cross-checking with the third author ( $\mathrm{S} \mathrm{Li})$. The extracted information included the following: name of the first author, year of publication, country of origin, radical descent, number of cases and controls, severity of disease, details of intervention, and outcome measures. Although the forms of Tai Chi are different, the intensity of aerobic activity is similar among them. The duration of exercise determines the load in sports. In this meta-analysis, a stratified analysis for duration was made. Additional information was collected through communication with the principal investigator by email if necessary.

\section{Outcome measures}

The primary outcomes were six-minute walking distance 


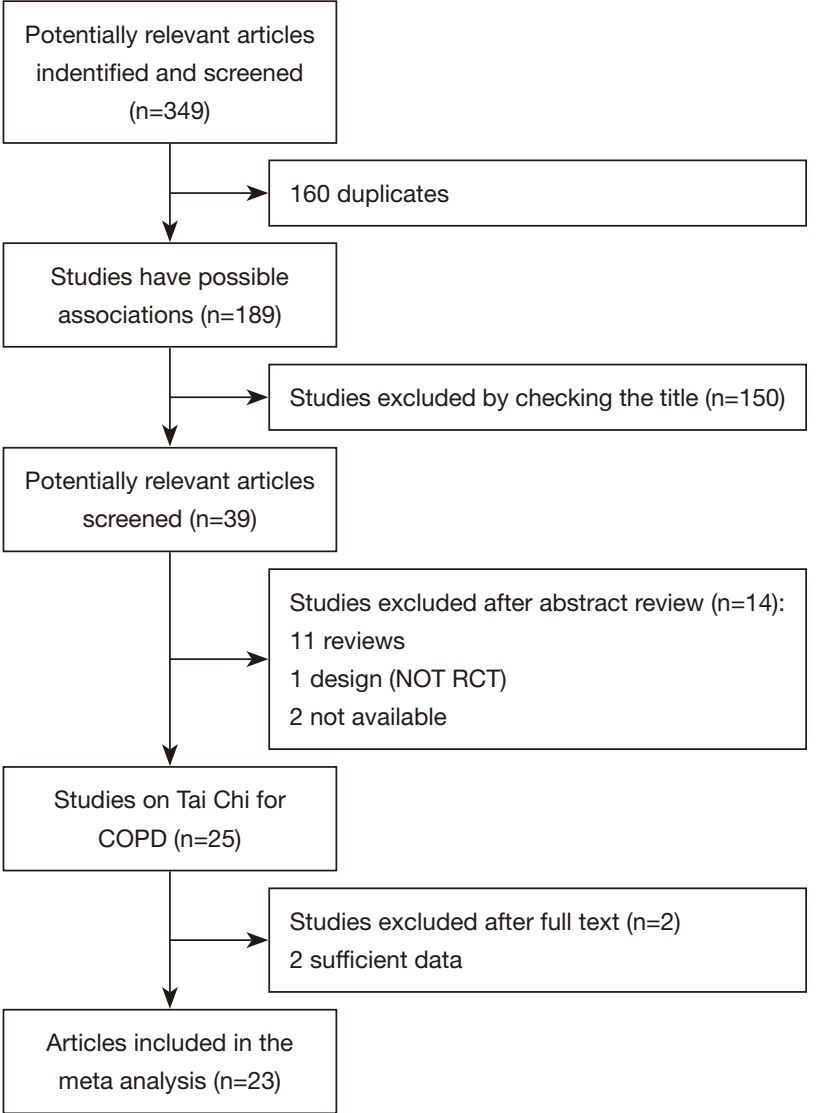

Figure 1 Study flow diagram. RCT, randomized controlled trials; COPD, chronic obstructive pulmonary disease.

(6MWD), which was used to evaluate exercise capacity, and lung function, which was used to degree of airway obstruction. This included percentage predicted forced expiratory flow volume in the first second (\% PredFEV $\left.V_{1}\right)$, forced volume capacity (FVC), and the ratio of $\mathrm{FEV}_{1}$ to FVC $\left(\mathrm{FEV}_{1} / \mathrm{FVC}\right)$. Versions of scores such as St. George's Respiratory Questionnaire (SGRQ), modified British medical research council (mMRC), the Borg scale, Chronic Respiratory Disease Questionnaire (CRQ), and the COPD assessment test (CAT) were common measures for evaluating the quality of life. There were also more uncommon outcomes, such as mental state examination, blood gas tensions $\left(\mathrm{PaCO}_{2}, \mathrm{PaO}_{2}\right)$, peripheral blood cluster of differentiation $4^{+} /$cluster of differentiation $8^{+}\left(\mathrm{CD}^{+} \%\right.$ $\mathrm{CD}^{+}$), and incremental shuttle walk test.

\section{Quality assessment}

The quality of the included studies was assessed using the
Cochrane risk of bias assessment tool (7). The content assessed included random sequences generation, allocation concealment, blinding of participants and personnel, blinding of outcome assessment, incomplete outcome data, selective outcome reporting, and other biases, evaluated as "low", "unclear" or "high". We assessed the quality of the included studies through consultations to reach a consensus.

\section{Statistical analysis}

Quantitative data were entered into the Review Manager Version 5.3.5 software program (The Cochrane Collaboration, London, UK). Eligible studies were analyzed using means and standard deviations to measure the change from baseline to endpoint in each intervention period. The mean difference (MD) and $95 \%$ confidence interval (CIs) were calculated to estimate the association strength. The chi-squared-based $\mathrm{Q}$ test and $\mathrm{I}^{2}$ metric were used to assess the between-study heterogeneity $\left(\mathrm{I}^{2}=0-25 \%\right.$ : low heterogeneity, $\mathrm{I}^{2}=25-50 \%$ : moderate heterogeneity, $\mathrm{I}^{2}=50-75 \%$ : large heterogeneity, and $\mathrm{I}^{2}=75-100 \%$ : extreme heterogeneity) (8). If $\mathrm{I}^{2}$ was less than $50 \%$, the fixedeffects method was used to produce the pooled estimates; otherwise, the random-effects method was adopted. Publication bias was assessed with Egger's and Begg's tests.

\section{Results}

\section{Results of the literature search}

There were 349 articles discussing the use of Tai Chi for COPD retrieved. The flowchart of study selection is presented in Figure 1.

\section{Study characteristics}

This review included 23 RCTs. Eight studies were published in English journals, and 15 studies were published in Chinese journals. A total of 1,663 COPD patients were assessed as part of this meta-analysis, recruited from hospitalizations, outpatient visits, and the community with a mean age ranging from 54 to 79 years and mean predicted $\mathrm{FEV}_{1}$ ranging from $30 \%$ to $80 \%$. One of the 23 selected studies was conducted in Australia (9), one was conducted in the United States (10), one was conducted in the United Kingdom (11), three were conducted in Hong Kong (12-14), and the rest were conducted in mainland China $(5,15-30)$. The study publication time ranged from 2004 to 2018.

There were three intervention types reflected among the 
included articles: 13 compared Tai Chi training against a blank control (usual care) $(5,9,10,12,13,15-18,22,24,29,30)$, seven compared Tai Chi training against an experimental control group adopting a breathing exercise regimen $(5,14,19,21,23,27,28)$; and 10 compared Tai Chi against other therapies including medication, yoga, breathing exercises, and pulmonary rehabilitation with a mutual control group $(5,11-13,16,17,20,22,25,26)$.

Regarding the style of Tai Chi, 14 studies adopted the simplified 24-form Yang style of Tai Chi $(5,11,16$ 22,24,26,28-30), two adopted the 13-form Qigong style of Tai Chi $(12,13)$, one adopted the Chen style of Tai Chi (27), one adopted the five-form Yang style of Tai Chi (10), one adopted the 21-form Sun style of Tai Chi (9), one adopted the five-form Sun style of Tai Chi (14), and three did not mention the style chosen $(15,23,25)$. Regarding the duration of intervention, some studies lasted from one to three months (9-14,16-18,20,24-27,30), some studies lasted from four to six months $(15,19,21,22,29)$, and others lasted for 12 months $(5,28)$. The duration and frequency of each Tai Chi session also varied amongst the included studies. The characteristics of the included studies are summarized in Table 1 .

\section{Outcome measures}

There were not exactly the same outcomes in the including studies. Eighteen studies examined changes in the quality of life using different scales (5,9-12,14-16,18,19,21,23$28,30)$. In particular, 14 studies used $6 \mathrm{MWD}$ to evaluate exercise capacity $(5,10,11,13,14,16,18,20,21,24-26,28,30)$; 12 studies assessed pulmonary function $(5,10,11,13-15,17$ 28,30); two studies examined Tai Chi and immunity using peripheral blood tumor necrosis factor- $\alpha$ (FNF- $\alpha$ ), interleukin (IL)-6, IL-8, and $\mathrm{CD}^{+} / \mathrm{CD}^{+}(20,21)$; and five studies considered the use of Tai Chi with respect to mental state examination outcomes $(9,10,15,17,19)$ such as the Symptom Checklist-90, Hospital Anxiety and Depression Scale (HAD), Self-rating Anxiety Scale (SAS); Self-rating Depression Scale (SDS), and Center for Epidemiologic Studies Depression Scale (CES-D).

\section{Risk of bias in included studies}

The details of the risk of bias among the 23 studies are displayed in Figure 2. Figure 3 presents a summary of our judgment on the potential risks of bias across all studies. A considerable number of studies reported incomplete details on randomization, blinding - especially blinding of participants and personnel—and withdrawal.

\section{Effects of interventions}

There were three intervention types of Tai Chi among the including studies, with additional details presented henceforth.

\section{Tai Chi vs. blank control (usual care)}

\section{MWD}

Eight studies, including a total of 624 participants, reported actual values of $6 \mathrm{MWD}$. The results showed the $6 \mathrm{MWD}$ was significantly enhanced in the Tai Chi group (MD 19.25m, 95\% CI: 14.71 to $23.80 ; \mathrm{P}<0.00001$ ) relative to the usual care group, with a big difference observed among the subgroups $(\mathrm{P}=0.03)$. However, the test for heterogeneity was significant ( $\mathrm{P}$ for heterogeneity $<0.00001, \mathrm{I}^{2}=79 \%$ ) (Figure $4 A$ ). Based on the analysis of the data, we detected the effect size of the two studies to be clearly abnormal from the others. Furthermore, if these two studies were excluded $(5,17)$, the heterogeneity was remarkably abated. The corrected result showed that the Tai Chi group was associated with a statistically significant improvement in 6MWD (MD $40.83 \mathrm{~m}, 95 \% \mathrm{CI}: 32.47$ to $49.19 \mathrm{~m}, \mathrm{P}<0.00001)$ using a fixed-effects model, and no heterogeneity between these studies was present ( $\mathrm{P}$ for heterogeneity $=0.45, \mathrm{I}^{2}=0 \%$ ) (Figure $4 B$ ).

\section{Percentage predicted forced expiratory flow volume in the first second $\left(\%\right.$ PredFEV $\left._{1}\right)$}

Eight studies $(\mathrm{n}=583)$ provided information regarding the $\%$ PredFEV $_{1}$. Pooled analysis showed that the Ti Chi group was associated with a statistically significant improvement in\%PredFEV ${ }_{1}$ (MD: 1.67\%, 95\% CI: 0.41-2.93; $\mathrm{P}=0.009$ ) when compared with the usual care group. Heterogeneity testing revealed low heterogeneity $(\mathrm{P}$ for heterogeneity $=$ $0.30, \mathrm{I}^{2}=15 \%$ ) (Figure 5).

\section{SGRQ}

Three studies, involving a total of 257 participants, used the SGRQ to evaluate the quality of life. The MD in the SGRQ was -9.22 (95\% CI: -14.67 to $-3.77 ; \mathrm{P}=0.0009$ ), and the heterogeneity test suggested high heterogeneity $\left(\mathrm{P}\right.$ for heterogeneity $=0.06, \mathrm{I}^{2}=64 \%$ ) (Figure $\left.6 A\right)$. Based on a statistical analysis of the data, if one study was excluded, no heterogeneity was present $(\mathrm{P}$ for heterogeneity $=0.98$, $\mathrm{I}^{2}=0 \%$ ) (Figure $6 B$ ) (15). The combined effect size showed 


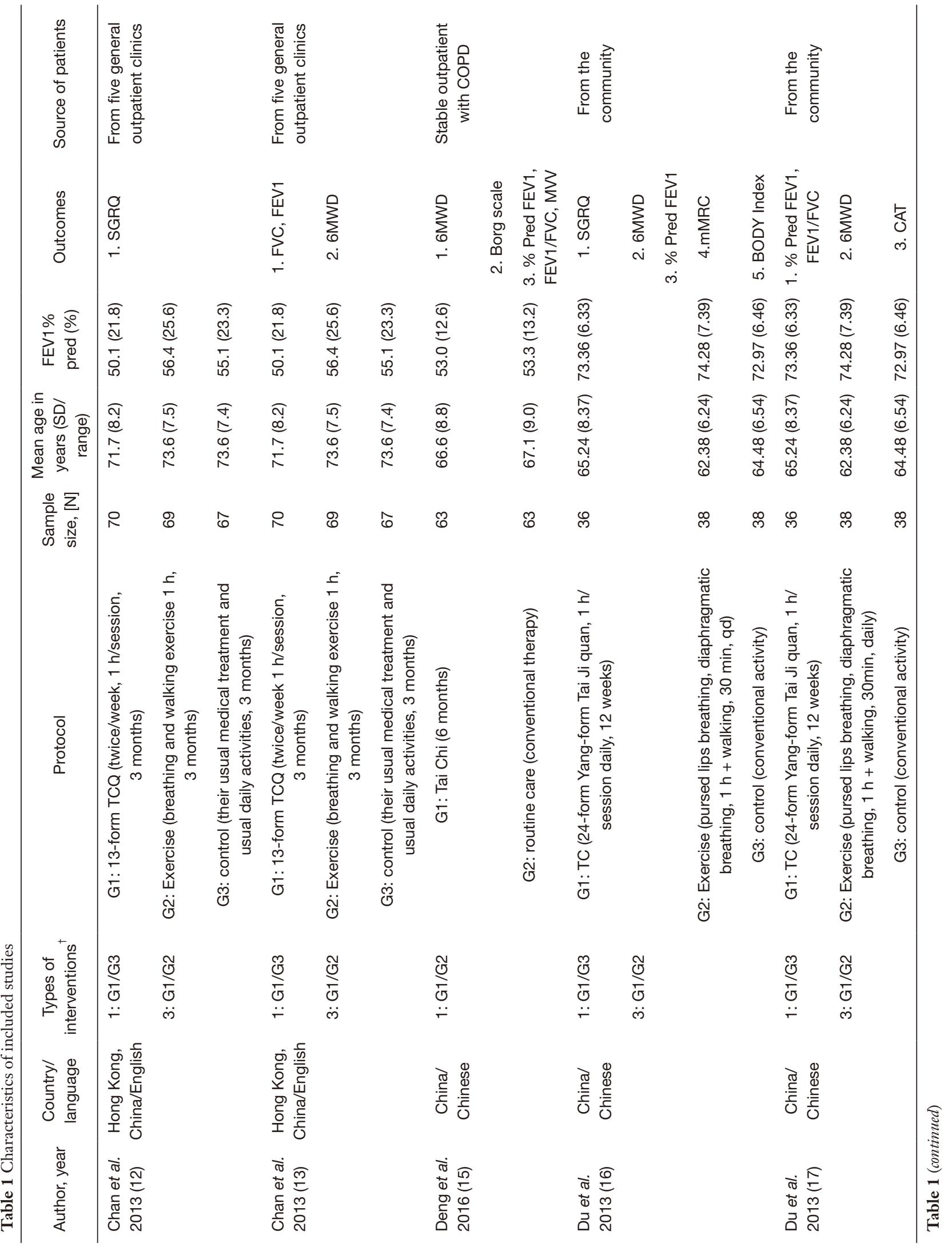




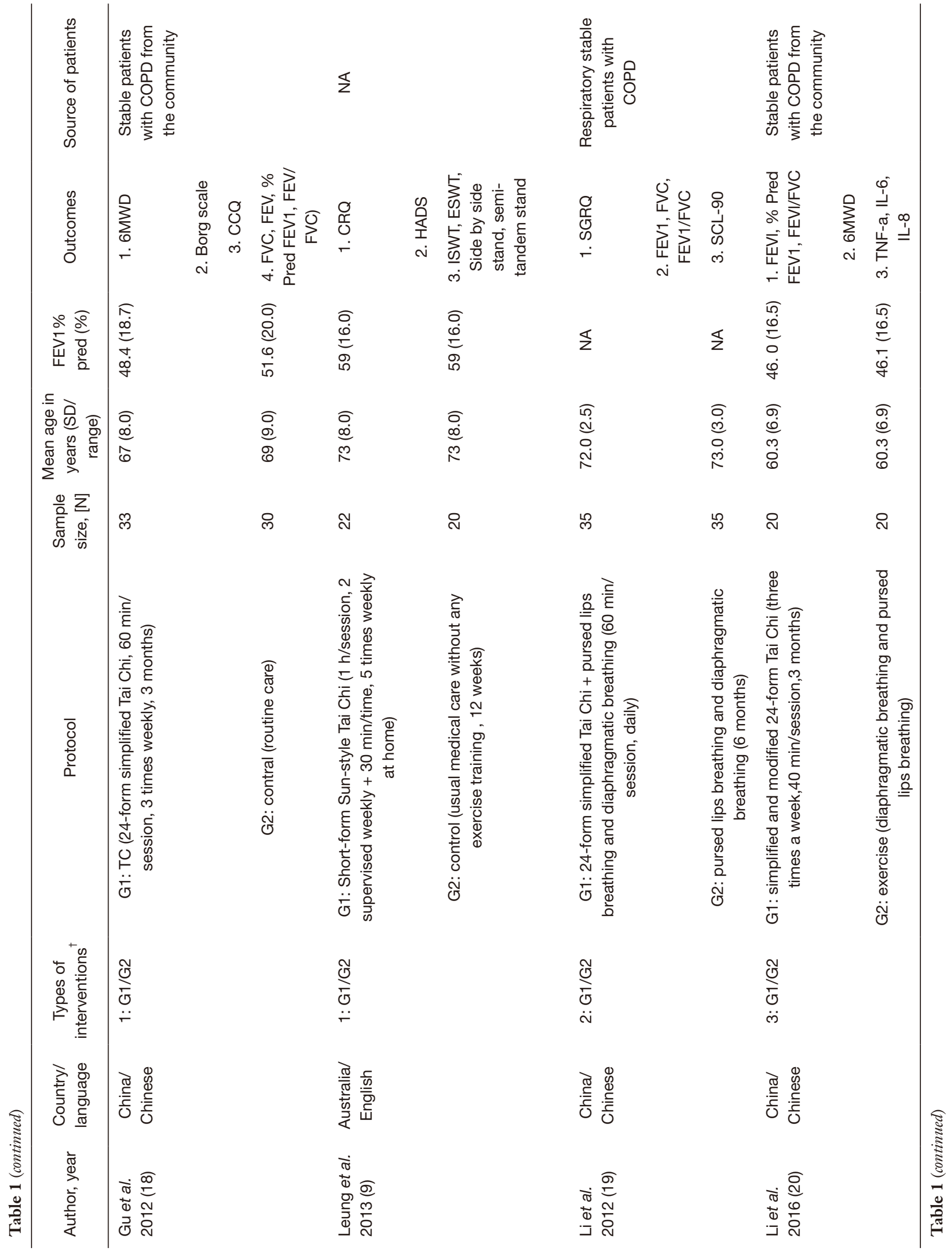




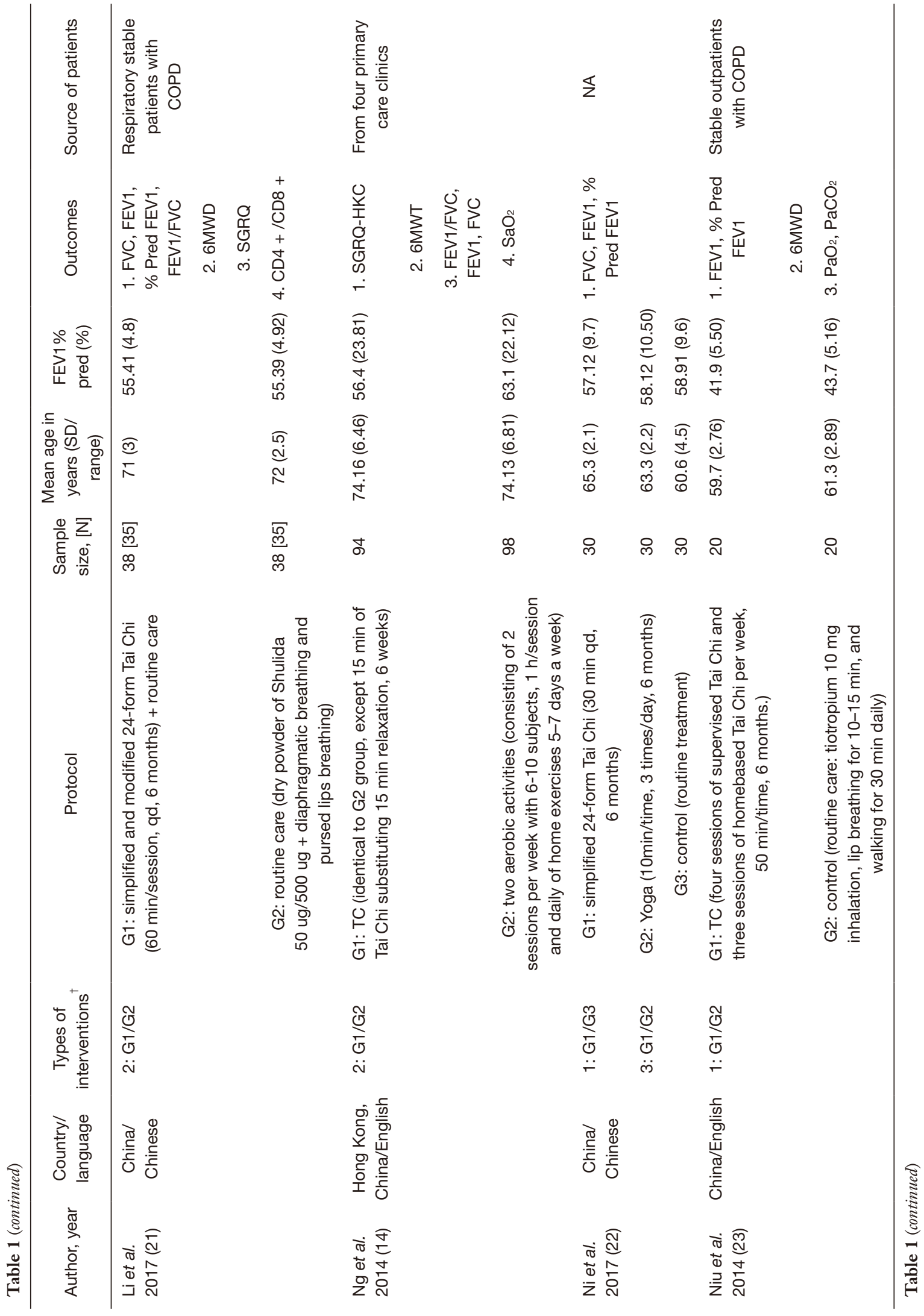




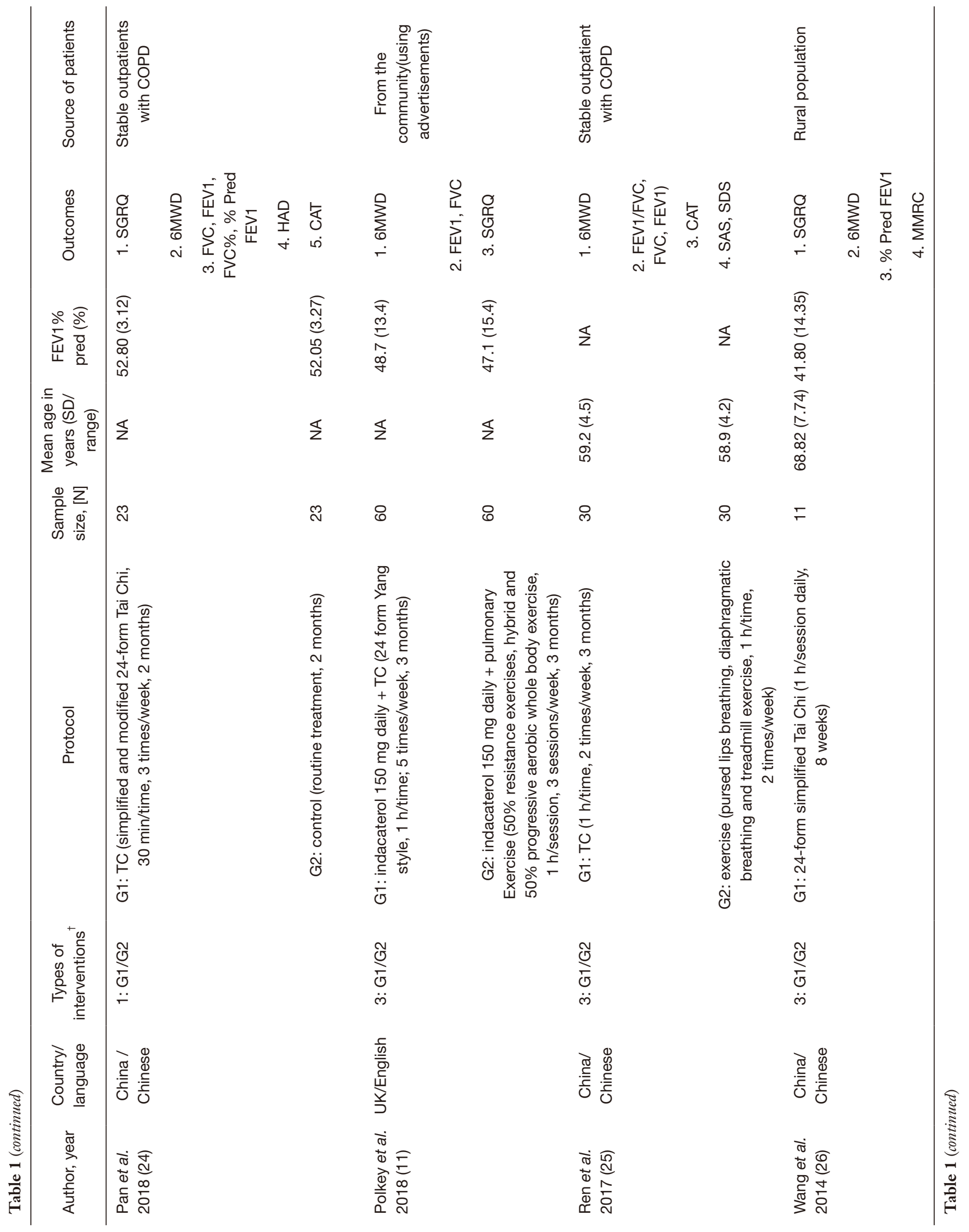




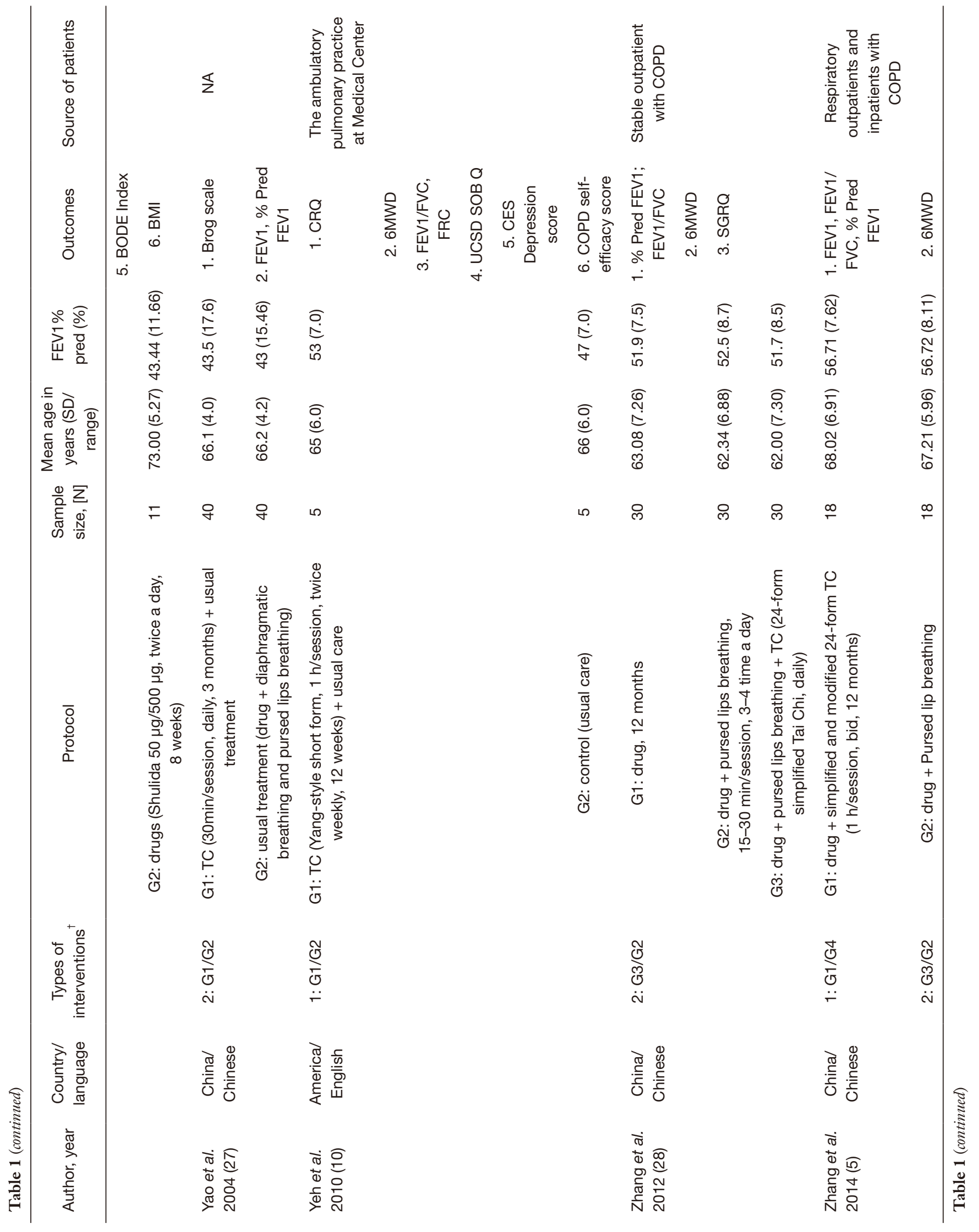




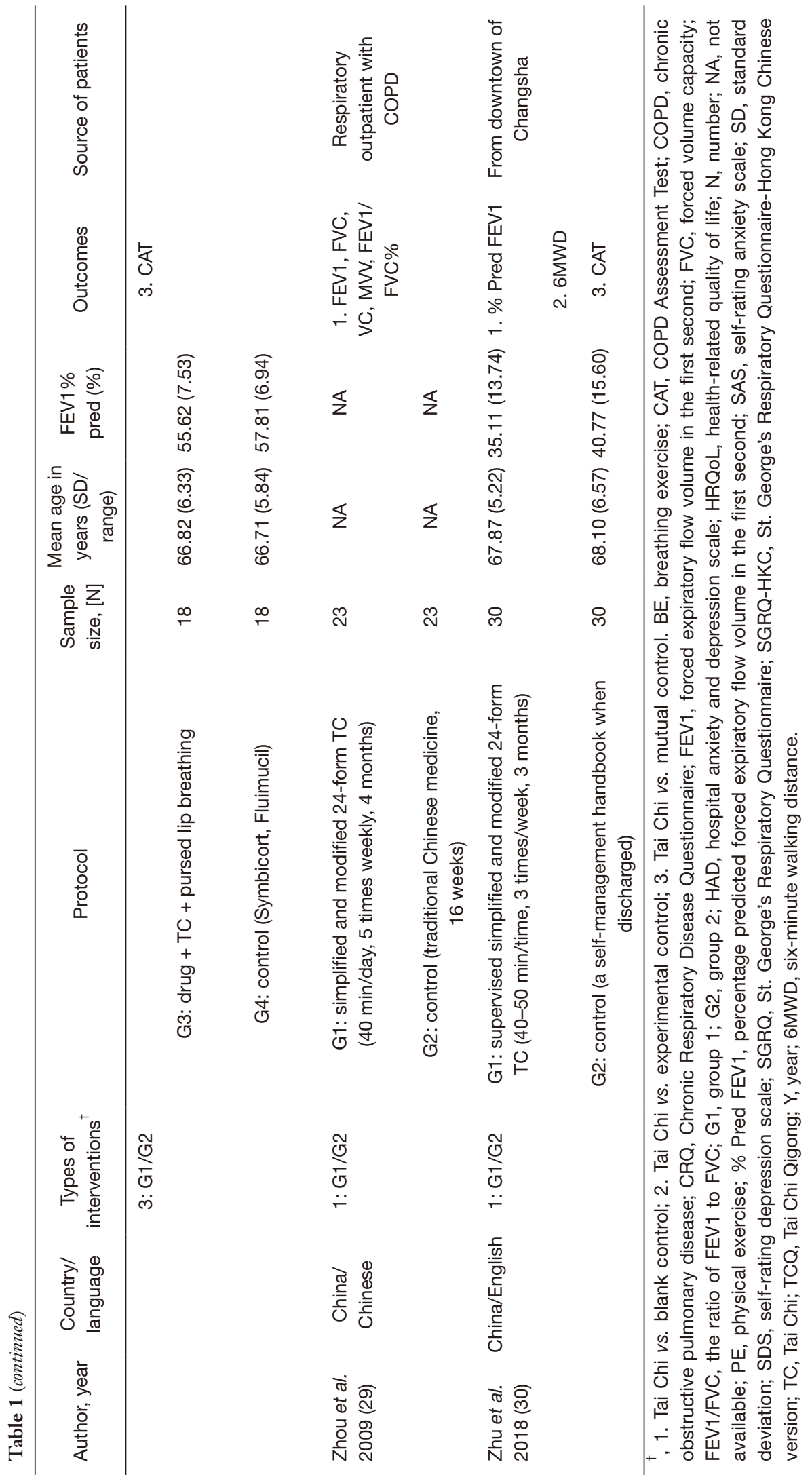




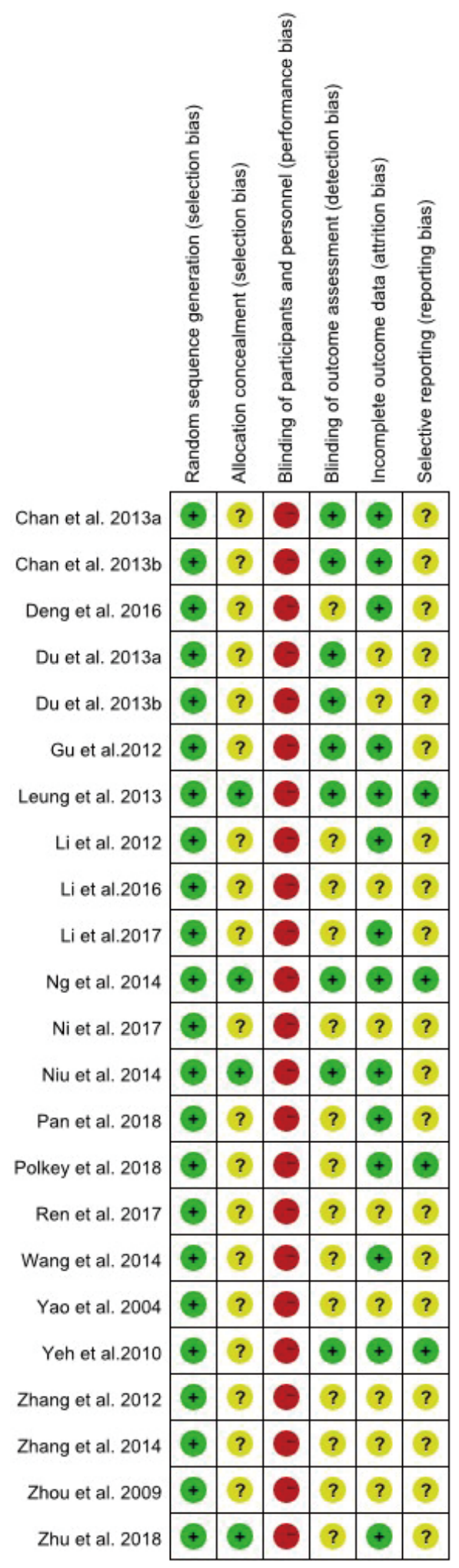

Figure 2 Risk of bias summary for included studies: review authors' judgments about each risk of bias item for each included study. that the Tai Chi group was associated with a significant improvement in SGRQ (MD: $-6.57,95 \%$ CI: -10.17 to $-2.98, \mathrm{P}=0.0003$ ) when compared with the usual care group.

\section{CRQ}

Two studies involving a total of 48 participants used the CRQ to evaluate changes in quality of life. The pooled effect size showed that the Tai Chi group experienced a significant improvement in the quality of life relative to the control group (MD: 1.60, 95\% CI: 0.89-2.30; $\mathrm{P}<0.00001$ ). No heterogeneity between studies was present ( $\mathrm{P}$ for heterogeneity $=0.37, \mathrm{I}^{2}=0 \%$ (Figure 7).

\section{CAT}

Four studies involving 288 participants used the CAT to evaluate changes in quality of life. The results indicated that the Tai Chi group had a lower CAT result than the control group (MD: $-3.66,95 \% \mathrm{CI}:-4.55$ to $-2.78 ; \mathrm{P}<0.00001$ ), while heterogeneity testing revealed low heterogeneity $(\mathrm{P}$ for heterogeneity $=0.29, \mathrm{I}^{2}=18 \%$ ) (Figure 8 ).

\section{Tai Chi vs. experimental control}

\section{MWD}

Five studies used 6MWD to evaluate exercise capacity, with 182 participants each in both the Tai Chi group and the breathing exercise control group. The results showed that the $6 \mathrm{MWD}$ was significantly enhanced in the Tai Chi group (MD: $14.15 \mathrm{~m}, 95 \% \mathrm{CI}: 3.76-24.53 \mathrm{~m}$; $\mathrm{P}=0.008$ ) as compared with the breathing exercise group, with no difference observed among the subgroups $(\mathrm{P}=0.68)$. Also, no heterogeneity between studies was present ( $\mathrm{P}$ for heterogeneity $=0.96, \mathrm{I}^{2}=0 \%$ ) (Figure 9).

\section{$\%$ PredFEV $_{1}$}

The $\%$ PredFEV $_{1}$ data were available from three studies involving 368 participants. No significant difference was shown in $\%$ PredFEV $_{1}$ between the Tai Chi group and the breathing exercise control group (MD: 0.62, 95\% CI: -1.18 to $2.42 ; \mathrm{P}=0.50$ ) (Figure 10).

\section{SGRQ}

Four studies including 694 participants examined the quality of life using SGRQ. No significant difference was shown in SGRQ score between the Tai Chi group and the breathing exercise control group (MD: $-1.82,95 \%$ CI: -4.29 to 0.66 ; $\mathrm{P}=0.15)$. No heterogeneity between studies was present $(\mathrm{P}$ for heterogeneity $=0.99, \mathrm{I}^{2}=0 \%$ ) (Figure 11). 


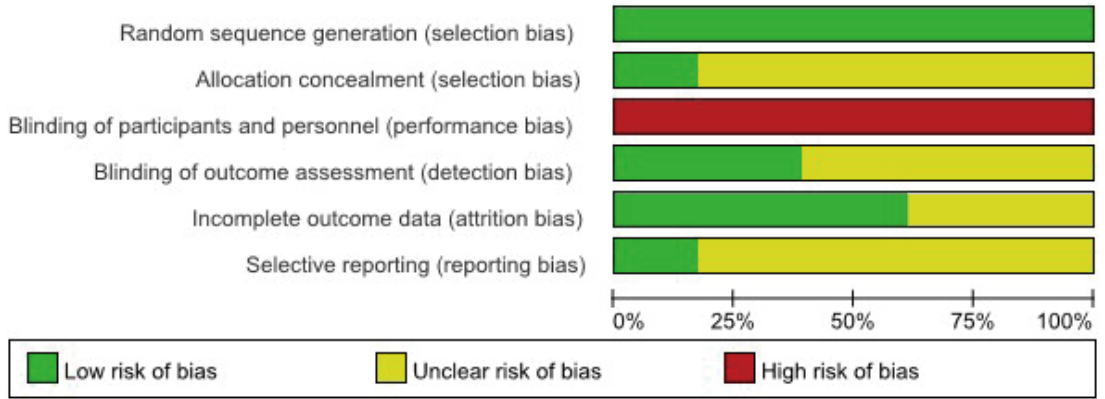

Figure 3 Risk of bias graph for included studies: review authors' judgments about each risk of bias item presented as percentages across all included studies.

\section{Tai Chi vs. mutual control (other therapy)}

\section{MWD}

Three studies involving 253 participants reported values of $6 \mathrm{MWD}$. No significant difference was shown in $6 \mathrm{MWD}$ between the Tai Chi group and the breathing and walking exercise group (MD: $16.72 \mathrm{~m}, 95 \%$ CI: -2.13 to $35.58 \mathrm{~m}$; $\mathrm{P}=0.08)$. The result of the heterogeneity test was significant ( $\mathrm{P}$ for heterogeneity $=0.11, \mathrm{I}^{2}=54 \%$ ) (Figure 12A); however, based on a statistical analysis of the data, if one study was excluded, no heterogeneity was present (20). Results also showed that $6 \mathrm{MWD}$ was increased in the Tai Chi group as compared with the breathing and walking exercise group (MD: $7.68 \mathrm{~m}, 95 \% \mathrm{CI}: 2.28-13.09$; $\mathrm{P}=0.005$ ). Here, no heterogeneity between the studies was present ( $\mathrm{P}$ for heterogeneity $\left.=0.35, \mathrm{I}^{2}=0 \%\right)$ (Figure 12B).

\section{SGRQ}

Two studies of 213 participants total examined the quality of life using SGRQ. The combined effect size showed that the Tai Chi group achieved a significant improvement in SGRQ (MD: $-5.31,95 \%$ CI: -9.13 to $-1.48 ; \mathrm{P}=0.007$ ) when compared with the breathing and walking exercise group. No heterogeneity between studies was present ( $\mathrm{P}$ for heterogeneity $=0.60, \mathrm{I}^{2}=0 \%$ ) (Figure 13).

\section{Sensitivity analysis}

The sample sizes of all pooled data were too small to construct funnel plots to explore potential publication bias.

\section{Discussion}

\section{Summary of the main results}

There remains no definitive conclusion that stable people with COPD benefit from Tai Chi. To further explore this issue, we conducted the present meta-analysis by collecting 23 RCTs covering 1,663 participants, regardless of language, dyspnea, exercise capacity, and quality of life. There were three interventions reported among the studies, including Tai Chi vs. blank control (usual care), Tai Chi $v s$. experimental control (most controls were breathing exercises), and Tai Chi vs. mutual control. The pooled data showed that the Tai Chi group was associated with significant improvements in $6 \mathrm{MWD}, \% \mathrm{PredFEV}_{1}, \mathrm{GRQ}$, CRQ, and CAT outcomes relative to the blank control. Meanwhile, the results showed incompletely consistent intervention effects between the Tai Chi group and the non-blank control group. When compared with the breathing exercise control group, 6MWD outcomes were significantly enhanced in the Tai Chi group, while there was no statistically significant difference in $\% \mathrm{PredFEV}_{1}$ or SGRQ between groups. As compared with the breathing and walking exercise group, the Tai Chi group showed a significant improvement in 6MWD and SGRQ. Current data suggested that Tai Chi might improve exercise capacity, pulmonary function, and quality of life among COPD patients. In other words, Tai Chi showed superior effects to those of breathing and walking exercise in promoting physical and psychosocial functions.

Clinical heterogeneity is influenced by many factors in this meta-analysis, including the baseline condition of patients with COPD (e.g., lung function, age), intervention measures (e.g., Tai Chi style, exercise time, duration, frequency), and outcome measurements (e.g., measuring method, quantitative measures, best time to measure). Chart 1 reveals the variation in clinical details. In this article, sources of heterogeneity were explored through subgroup meta-analyses with different durations. Three studies $(19,21,23)$ lasted for six months, and two studies $(5,28)$ 


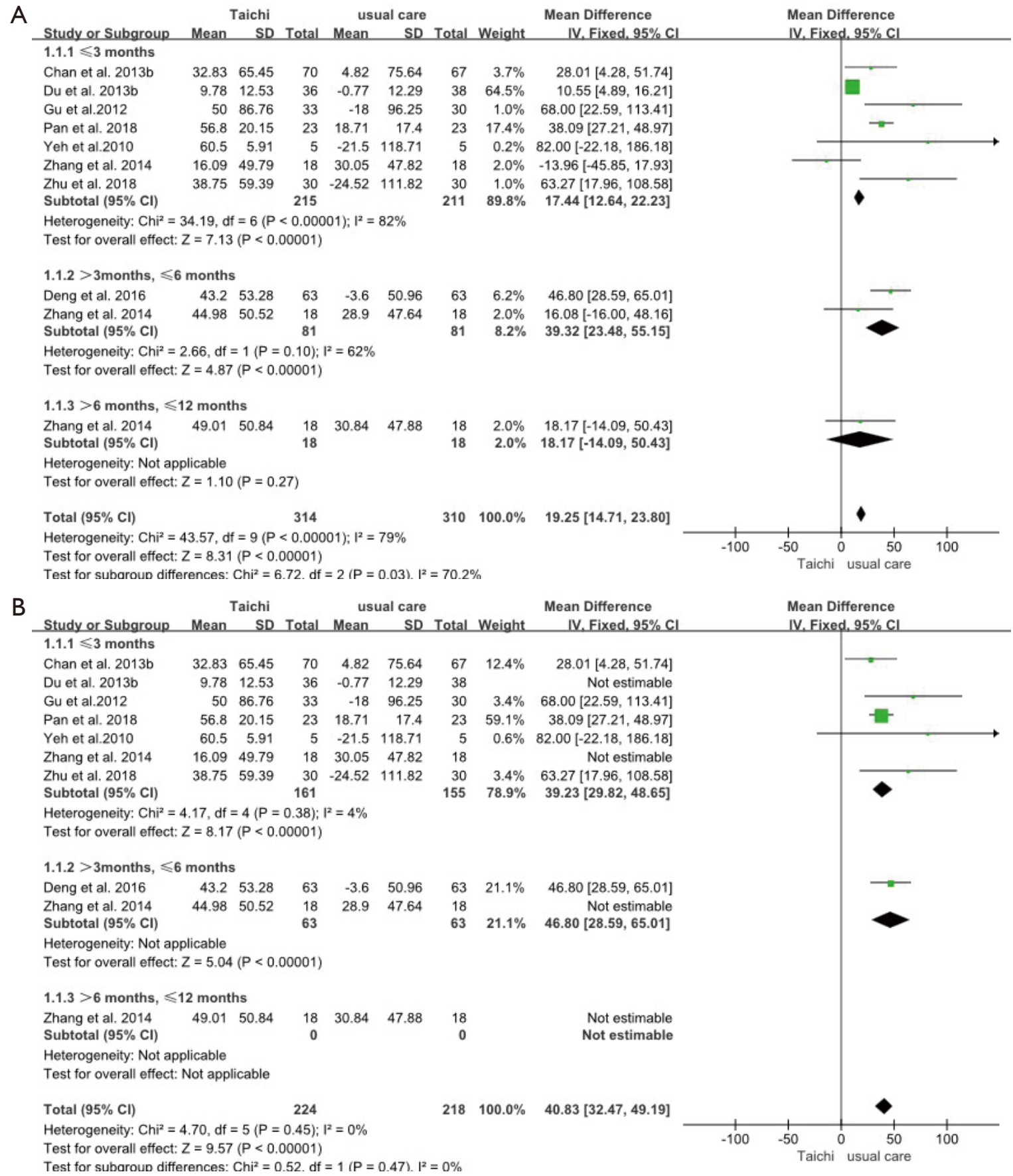

Figure 4 Forest plot of comparison: Tai Chi vs. blank control (usual care), outcome: 6-minutewalk distance. (A) Comparison of all included studies. (B) Comparison after adjusting the heterogeneity.

lasted for 12 months. The results showed that, over time, Tai Chi promoted a benefit in CAT results relative to the blank control and 6MWD outcomes relative to breathing exercise.
Among the selected literature, one study reported balance and strength outcomes associated with Tai Chi practice in patients with COPD (9). Two studies researched Tai Chi and immunity using different indicators $(20,21)$. 


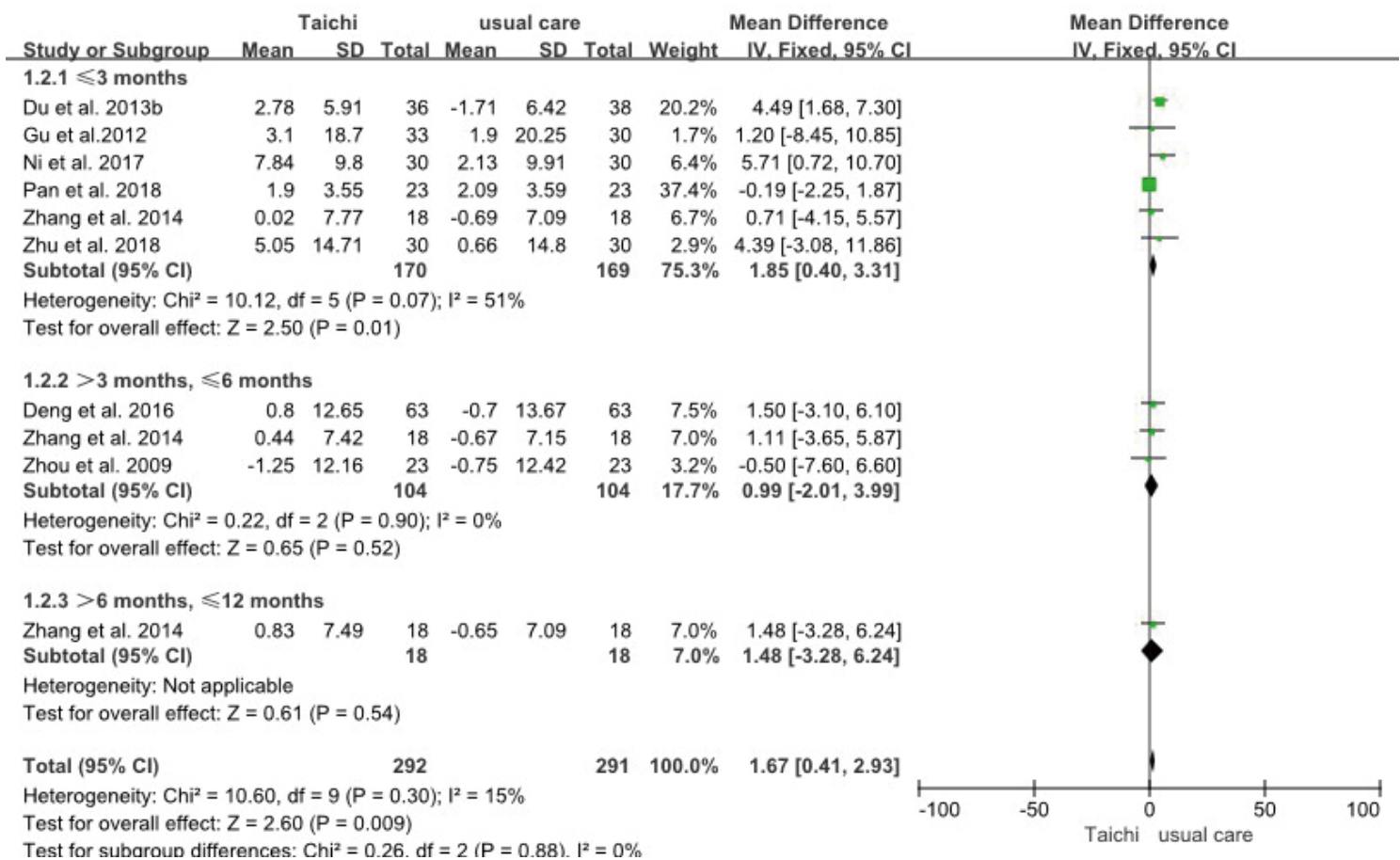

Figure 5 Forest plot of comparison: Tai Chi vs. blank control (usual care), outcome: percentage predicted forced expiratory flow volume in the first second.

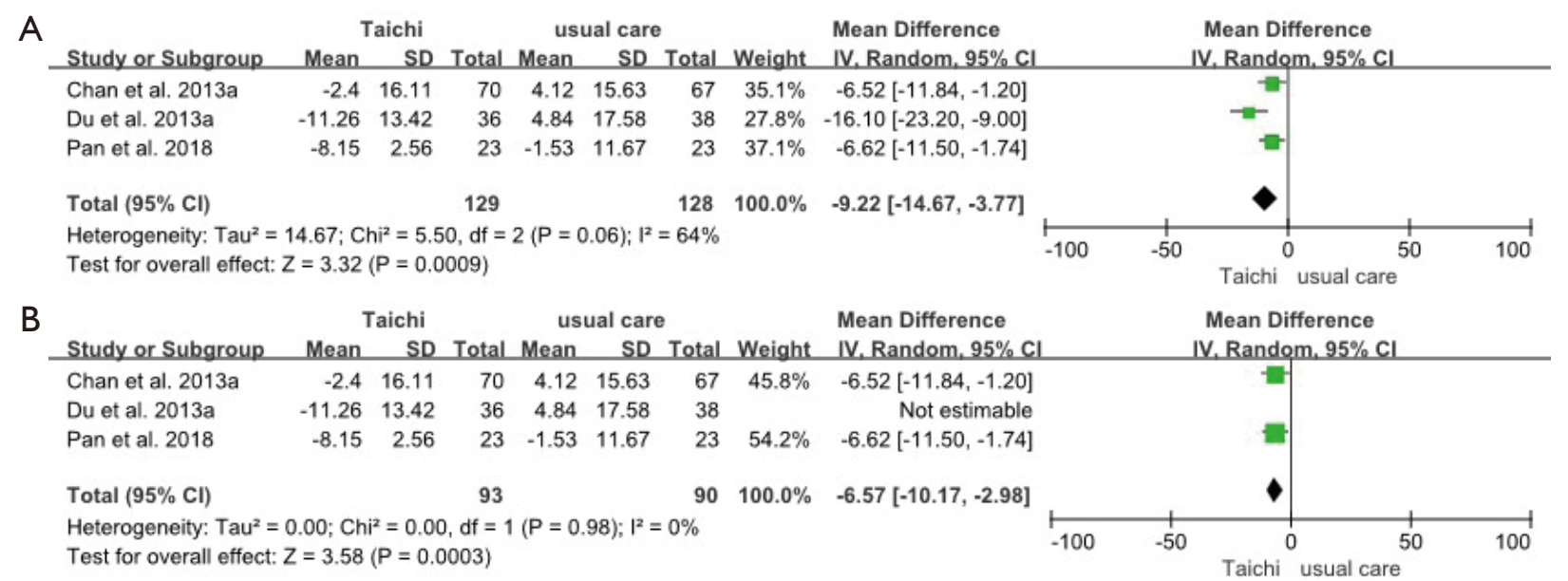

Figure 6 Forest plot of comparison: Tai Chi vs. blank control (usual care), outcome: St. George's Respiratory Questionnaire. (A) Comparison of all included studies. (B) comparison after adjusting the heterogeneity.

The change in peripheral blood FNF- $\alpha$, IL-6, IL-8, and CD4+/CD8+ contents during Tai Chi showed that it might help improve immunity. Five studies researched Tai Chi and psychological well-being using different indicators in different interventions $(9,10,15,17,19)$. One study compared pulmonary rehabilitation alone (two aerobic activities) with Tai Chi elements added to a pulmonary rehabilitation regimen (14). One study considered Tai Chi in comparison with pulmonary rehabilitation (resistance exercise, hybrid, and aerobic whole-body exercises) (11). One study assessed 


\begin{tabular}{|c|c|c|c|c|c|c|c|c|c|c|c|c|}
\hline \multirow[b]{2}{*}{ Study or Subgroup } & \multicolumn{2}{|c|}{ Taichi } & \multicolumn{4}{|c|}{ usual care } & \multirow{2}{*}{\multicolumn{2}{|c|}{$\begin{array}{c}\text { Mean Difference } \\
\text { Weight IV.Fixed. } 95 \% \text { CI }\end{array}$}} & \multirow{2}{*}{\multicolumn{4}{|c|}{$\begin{array}{l}\text { Mean Difference } \\
\text { IV.Fixed. } 95 \% \mathrm{CI}\end{array}$}} \\
\hline & Mean & SD & Total & Mean & SD & Total & & & & & & \\
\hline Leung et al. 2013 & 0.6 & 5 & 19 & 0 & 1 & 19 & $9.4 \%$ & $0.60[-1.69,2.89]$ & & & $t$ & \\
\hline Yeh et al.2010 & 1.48 & 0.64 & 5 & -0.22 & 0.55 & 5 & $90.6 \%$ & $1.70[0.96,2.44]$ & & & & \\
\hline Total $(95 \% \mathrm{Cl})$ & & & 24 & & & 24 & $100.0 \%$ & $1.60[0.89,2.30]$ & & & & \\
\hline $\begin{array}{l}\text { Heterogeneity: } \mathrm{Chi}^{2}= \\
\text { Test for overall effect: }\end{array}$ & $\begin{array}{l}0.80, d f \\
Z=4.44\end{array}$ & $\begin{array}{l}=1(P= \\
(P<0\end{array}$ & $\begin{array}{l}0.37) ; \\
00001\end{array}$ & $i^{2}=0$ & & & & & -100 & -50 & 0 & 100 \\
\hline
\end{tabular}

Figure 7 Forest plot of comparison: Tai Chi vs. blank control (usual care), outcome: Chronic Respiratory Disease Questionnaire.

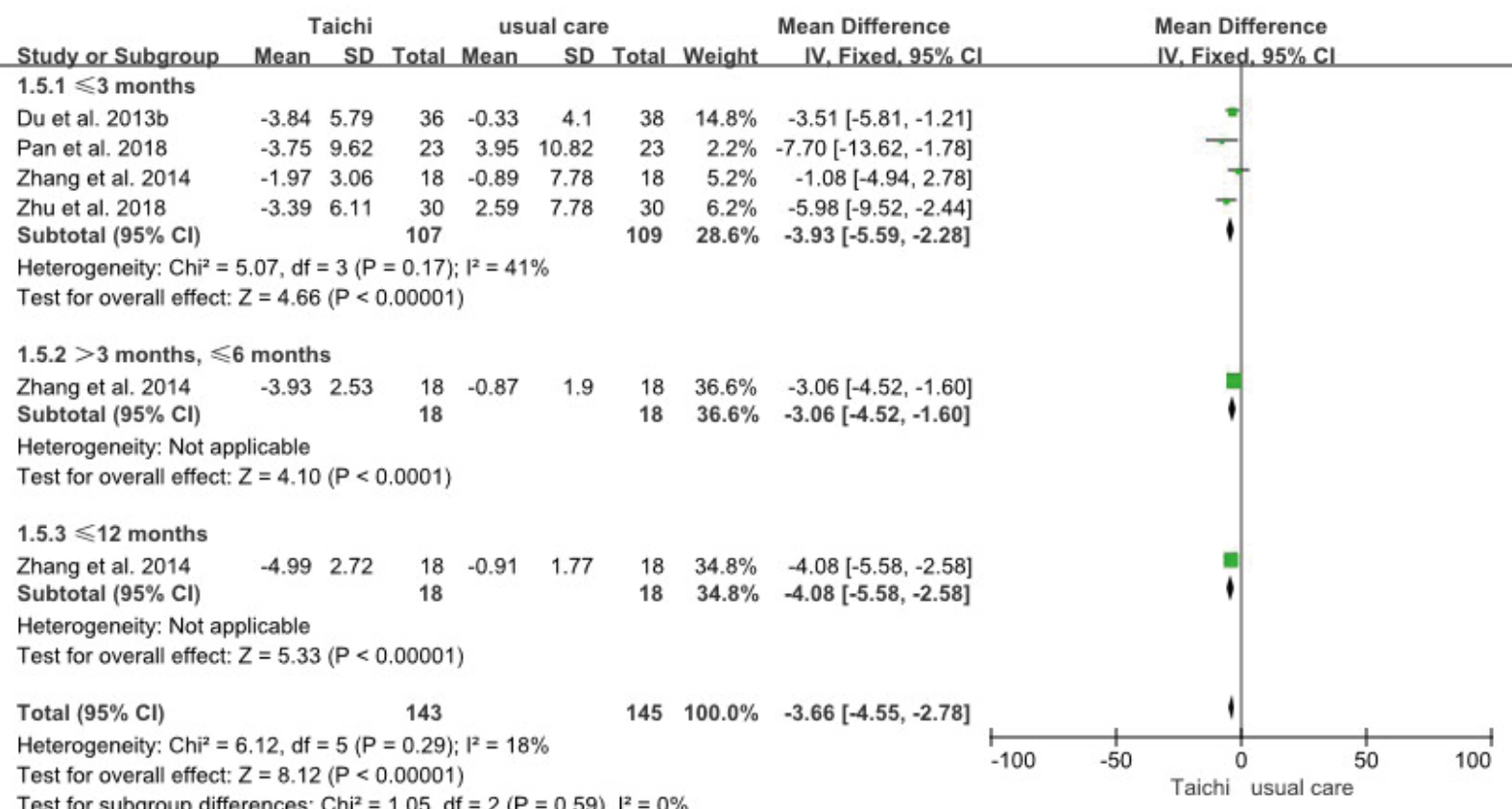

Figure 8 Forest plot of comparison: Tai Chi vs. blank control (usual care), outcome: COPD Assessment Test.

Tai Chi in comparison with breathing exercises (breathing with pursed lips, diaphragmatic breathing) and treadmill exercise (25). One study considered Tai Chi in contrast with medication. As such, the above data from different interventions could not be pooled (26). Also, only five studies $(10,11,23-25)$ paid attention to the adverse events, and one study (11) reported the reasons for hospitalization during intervention.

\section{Overall completeness and applicability of Evidence}

All recruited participants were diagnosed with COPD according to the GOLD, the American Thoracic Society, and the Chinese Thoracic Society guidelines. In most of the studies, the severity of COPD ranged from moderate to severe; however, there were three studies where the severity of COPD ranged from mild to very severe $(11,14,30)$. Therefore, one cannot apply the same results equally to all patients with COPD. Twenty studies were conducted in Southeast Asia, while the rest were performed in the United Kingdom, Australia, or the United States. Only one of the non-Asian studies definitely described the ethnicity of the participants, the sample size of which was 10 patients (10). Therefore, the results should be applied to non-Asian populations cautiously.

Age affects the basic state of the whole body, including the immune state, muscle motor ability, and lung function. No study included in this meta-analysis involved age stratification. Different forms, durations, and intensities of Tai Chi led to an inability to accurately quantify the exercise. Also, the outcome measures were not exactly the same across the studies. Despite these considerations, 


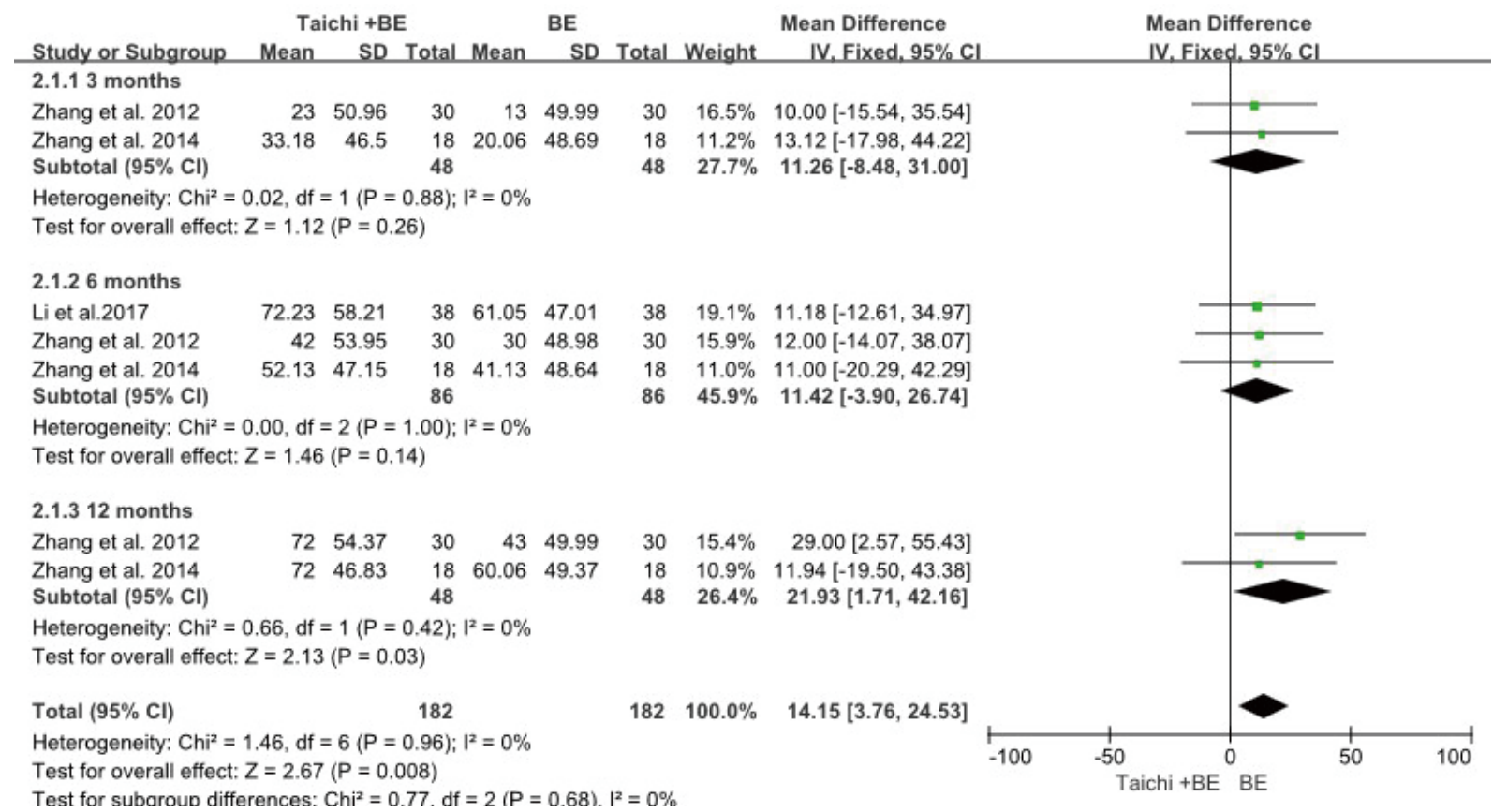

Figure 9 Forest plot of comparison: Tai Chi vs. experimental control, outcome: six-minute walking distance.

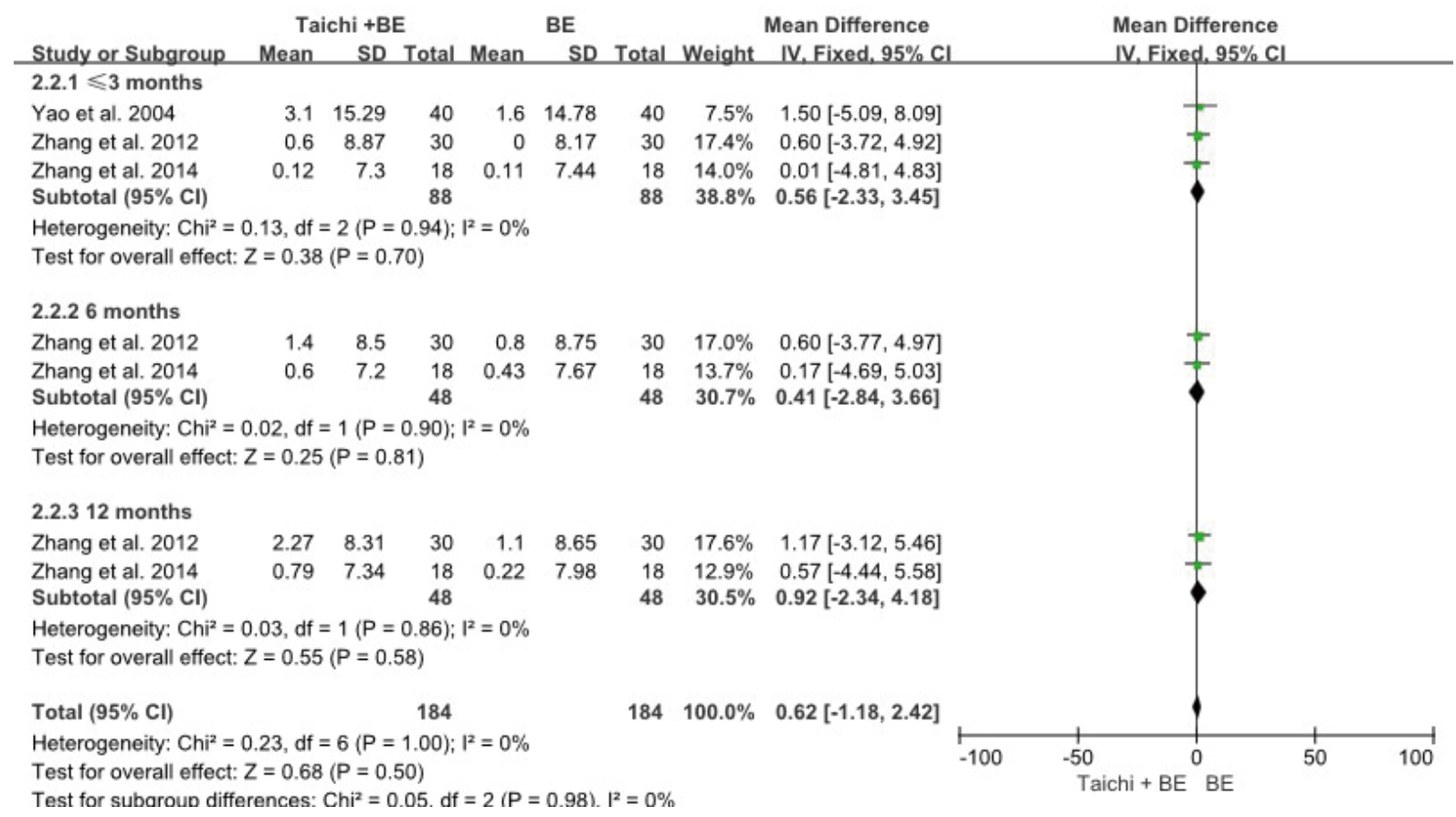

Figure 10 Forest plot of comparison: Tai Chi vs. experimental control (breathing exercise), outcome: percentage predicted forced expiratory flow volume in the first second. 


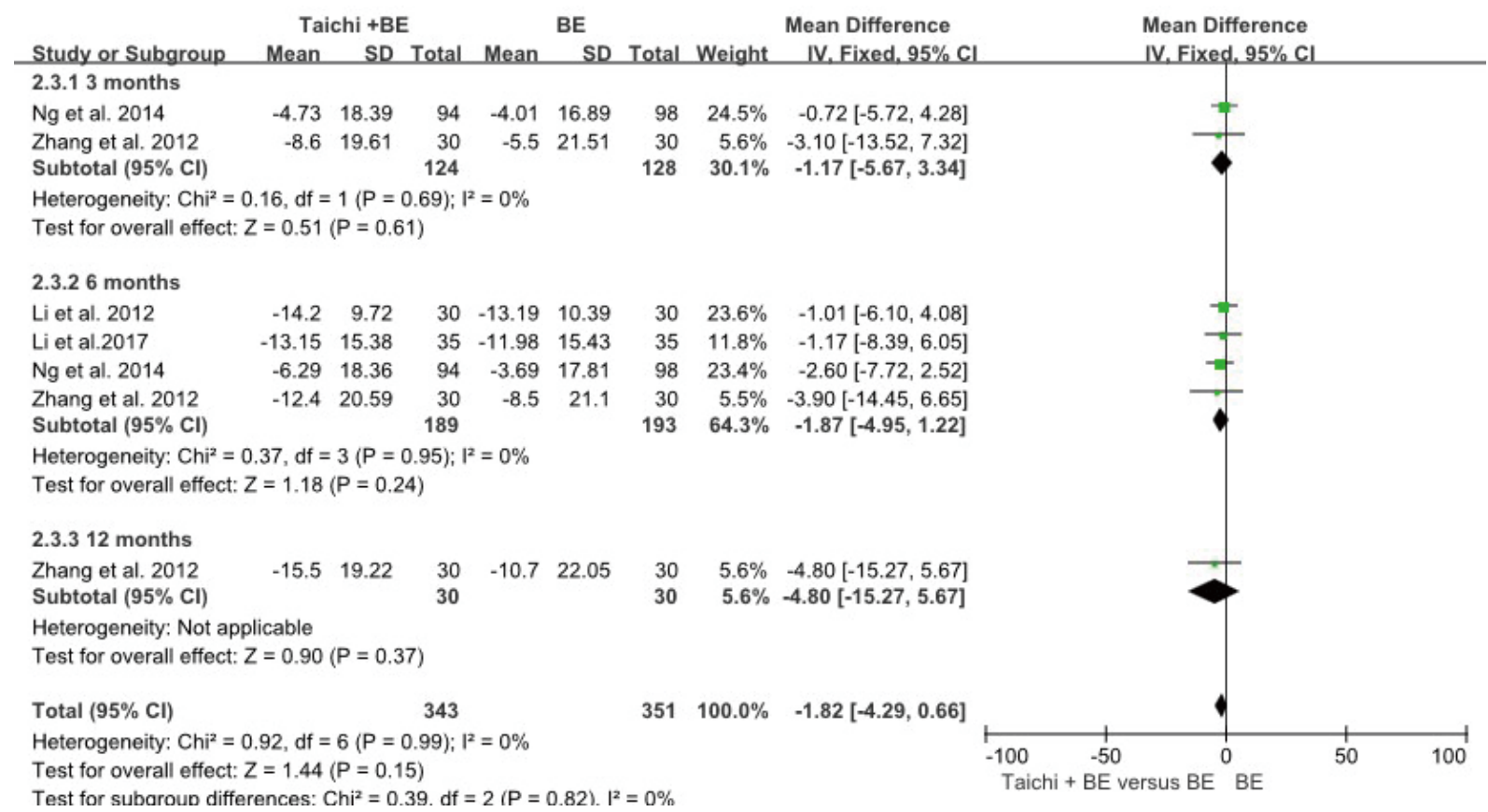

Figure 11 Forest plot of comparison: Tai Chi vs. experimental control (breathing exercise), outcome: St. George's Respiratory Questionnaire.

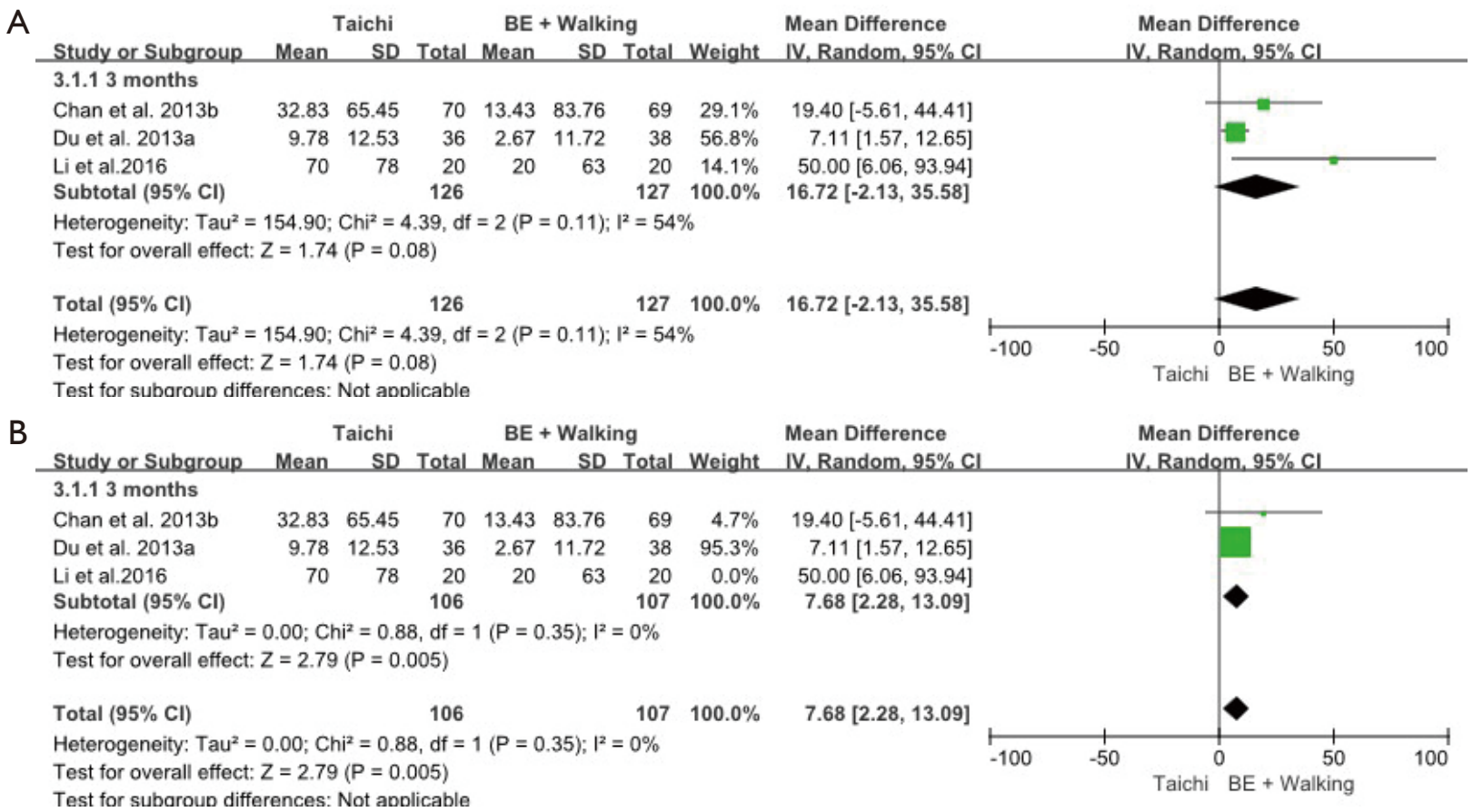

Figure 12 Forest plot of comparison: Tai Chi vs. breathing and walking exercise, outcome: six-minute walking distance. (A) Comparison of all included studies. (B) comparison after adjusting the heterogeneity. 


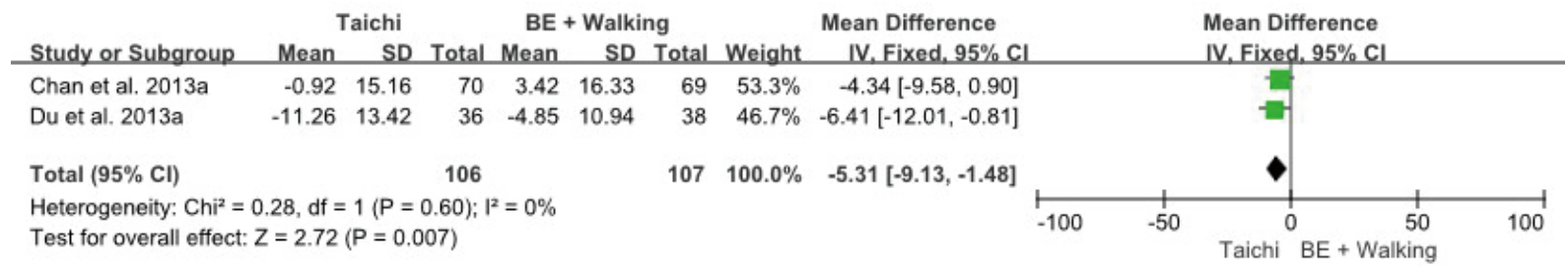

Figure 13 Forest plot of comparison: Tai Chi vs. breathing and walking exercise, outcome: St. George's Respiratory Questionnaire.

findings of improved exercise capacity and dyspnea were consistent.

\section{Quality of the evidence}

Our assessment of the risk of bias revealed that about four studies $(9,10,14,23)$ showed a low risk of bias, and 12 studies $(11-13,15-19,21,24,26,30)$ showed a moderate risk of bias. All studies mentioned randomization, including 16 that reported their randomization methods $(5,9,10,12-14,16-$ 20,22-25,30). Meanwhile, four were graded as having a low risk of allocation concealment $(9,14,23,30)$, and the rest were not clearly described. Tai Chi is a widespread exercise with fixed postures, and the blinding of participants is unfeasible during the intervention process, which directly leads to performance bias. There were nine studies $(9,10,12-14,16-18,23)$ mentioning blinding of the outcome assessments that showed a low risk of detection bias. Three studies reported an intention-to-treat (ITT) analysis $(10,12-14)$, while most of the studies reported dropouts and used per-protocol analysis; seldom did studies not report a dropout rate. There were four studies $(9-11,14)$ with a preregistered protocol among the 23 included studies, and these were assessed to show a low risk of selective reporting. Therefore, the results of this meta-analysis were influenced by methodological heterogeneity.

\section{Potential biases in the review process}

The sample size of all pooled data was less than 10, which restricted the use of funnel plots to explore publication bias. However, this limitation did not influence the observation of potential biases. First, the articles retrieved mostly showed positive results. Second, the selection bias of included studies, especially allocation concealment, could induce false-positive results. In addition, different types of funding affected the papers published. Finally, language limitations (English and Chinese) produced inclusion criteria bias.

\section{Agreements and disagreements with other studies or reviews}

Currently, there are four reviews available researching Tai Chi for COPD. All of the studies report a degree of benefit from Tai Chi for COPD. The meta-analysis by $\mathrm{Ng}$ et al. showed that the Qigong/Tai Chi group had better $\mathrm{FEV}_{1} /$ FVC and 6MWD outcomes when compared with the conventional exercise group (31). This systematic review supports the therapeutic value of Qigong/Tai Chi in patients with COPD. Meanwhile, the meta-analysis by $\mathrm{Wu}$ et al. examined the effectiveness of meditation movements, which included Tai Chi, yoga, and Qigong (4). Their results suggested that meditative movement may have the potential to enhance lung function and PA in COPD patients. The meta-analysis by Ding et al. demonstrated that, relative to no exercise, Tai Chi had significant effects on $6 \mathrm{MWD}$, $\mathrm{FEV}_{1}, \% \operatorname{PredFEV}_{1}$, and the SGRQ score (32). There were no significant differences in all outcomes between Tai Chi and other exercise training groups except for 6MWD. The results of Yan et al. revealed that Tai Chi was associated with statistical improvements in $6 \mathrm{MWD}$, dyspnea, $\mathrm{FEV}_{1}$, and FVC (33). Tai Chi significantly improved both the CRQ and SGRQ results. These findings suggest that Tai Chi may represent an effective alternative means by which to achieve results similar to those reported following participation in pulmonary rehabilitation programs. The meta-analysis by Ngai et al. found that the Tai Chi group was associated with a significant improvement in $6 \mathrm{MWD}$ and pulmonary function when compared with the usual care group (34). Finally, the meta-analysis considering the safety of Tai Chi by Wayne et al. showed that Tai Chi was unlikely to result in serious adverse events (35).

\section{Conclusions}

Current data suggest that Tai Chi might improve exercise 
capacity, pulmonary function, and quality of life among COPD patients as compared with no treatment. Tai Chi might have superior effects to those of breathing and walking exercises in promoting exercise capacity and psychosocial functions. Tai Chi might promote greater exercise capacity relative to breathing exercises alone. Overall, people with COPD may obtain benefit from Tai Chi, and advisable exercise intensity and no special equipment are advantages of Tai Chi.

To better assess the influence of Tai Chi on COPD, it is necessary to conduct high-quality RCTs, considering strict randomization, intention-to-treat analysis, and selective reporting. More articles on Tai Chi in different directions are needed to confirm the effects of Tai Chi.

\section{Acknowledgments}

Funding: This study was supported by the National Key Research and Development Program of China (No. 2018YFC1313600), the National Natural Science Foundation of China (Nos. 81570081 and 81770083), and the Natural Science Foundation of Fujian Province (No. 2017J01140).

\section{Footnote}

Reporting Checklist: The authors have completed the PRISMA Reporting checklist. Available at http://dx.doi. org/10.21037/apm-20-940

Conflicts of Interest: All authors have completed the ICMJE uniform disclosure form (available at http://dx.doi. org/10.21037/apm-20-940). The authors have no conflicts of interest to declare.

Ethical Statement: The authors are accountable for all aspects of the work in ensuring that questions related to the accuracy or integrity of any part of the work are appropriately investigated and resolved.

Open Access Statement: This is an Open Access article distributed in accordance with the Creative Commons Attribution-NonCommercial-NoDerivs 4.0 International License (CC BY-NC-ND 4.0), which permits the noncommercial replication and distribution of the article with the strict proviso that no changes or edits are made and the original work is properly cited (including links to both the formal publication through the relevant DOI and the license).
See: https://creativecommons.org/licenses/by-nc-nd/4.0/.

\section{References}

1. Vestbo J, Hurd SS, Agustí AG, et al. Global strategy for the diagnosis, management, and prevention of chronic obstructive pulmonary disease: GOLD executive summary. Am J Respir Crit Care Med 2013;187:347-65.

2. Fontana JA, Colella C, Wilson BR, et al. The energy costs of a modified form of T'ai Chi exercise. Nurs Res 2000;49:91-6.

3. Lan C, Chen SY, Wong MK, et al. Tai Chi training for patients with coronary heart disease. Med Sport Sci 2008;52:182-94.

4. Wu LL, Lin ZK, Weng HD, et al. Effectiveness of meditative movement on COPD: a systematic review and meta-analysis. Int J Chron Obstruct Pulmon Dis 2018;13:1239-50.

5. Zhang XC, Cai YL, Zhang W, et al. 24-form Tai Chi Quan combined with breathing exercise and western medicine for patients with stable obstructive pulmonary disease. J Tradit Chin Med 2014;55:1937-41.

6. Moher D, Liberati A, Tetzlaff J, et al. Preferred reporting items for systematic reviews and meta-analyses: the PRISMA statement. BMJ 2009;339: b2535.

7. Higgins JP, Green S. Cochrane handbook for systematic reviews of interventions version 5.0.2 [updated September 2009]. Oxford: The Cochrane Collaboration, 2009.

8. Higgins JP, Thompson SG, Deeks JJ, et al. Measuring inconsistency in meta-analyses. BMJ 2003;327:557-60.

9. Leung RW, McKeough ZJ, Peters MJ, et al. Short-form Sun-style t'ai chi as an exercise training modality in people with COPD. Eur Respir J 2013;41:1051-7.

10. Yeh GY, Roberts DH, Wayne PM, et al. Tai chi exercise for patients with chronic obstructive pulmonary disease: a pilot study. Respir Care 2010;55:1475-82.

11. Polkey MI, Qiu ZH, Zhou L, et al. Tai Chi and Pulmonary Rehabilitation Compared for Treatment-Naïve Patients With COPD: A Randomized Controlled Trial. Chest 2018;153:1116-24.

12. Chan AW, Lee A, Lee DT, et al. Evaluation of the sustaining effects of Tai Chi Qigong in the sixth month in promoting psychosocial health in COPD patients: a singleblind, randomized controlled trial. ScientificWorldJournal 2013;2013:425082.

13. Chan AW, Lee A, Lee DT, et al. The sustaining effects of Tai chi Qigong on physiological health for COPD patients: a randomizedcontrolled trial. Complement Ther 
Med 2013;21:585-94.

14. Ng L, Chiang LK, Tang R, et al. Effectiveness of incorporating Tai Chi in a pulmonary rehabilitation program for chronic obstructive pulmonary disease (COPD) in primary care-A pilot randomized controlled trial. Eur J Integr Med 2014;6:248-58.

15. Deng ZX, Chen $\mathrm{H}, \mathrm{Xu} \mathrm{ZB}$, et al. The role of Taijiquan in stable chronic obstructive pulmonary disease. Journal of Anhui Vocational and Technical Institute of Health 2016;15:18-9.

16. Du ST, Xing B, Wang CX, et al. The effects of Taijiquan practice on the BODE and SGRQ of COPD patients. Chin J Sports Med 2013;32:403-7.

17. Du ST, Ding LM, Wang CX, et al. Effectiveness of Taijiquan on exercise endurance and pulmonary function in patients with chronic obstructive pulmonary disease. Chin J Rehabil Med 2013;28:374-6.

18. Gu G, Zhou YM, Wang DL, et al. Effects of shadow boxing training on exercise endurance and quality of life of patients with chronic obstructive pulmonary disease. Zhonghua Yi Xue Za Zhi 2012;92:952-5.

19. Li Q, Fang WH, Liu C. The effects of Taijiquan combined with respiratory exercise training on rehabilitation of patients with stable chronic obstructive pulmonary disease. Chin J Rehabil Med 2012;27:825-8.

20. Li SX, Li AJ, Sun J, et al. Effects of Tai Chi Quan rehabilitation in patients with chronic obstructive pulmonary disease. Journal of Binzhou medical college 2016;39:275-7.

21. Li Q, Fang WH, Liu C, et al. Effects of seretide combined with Tai Chi on severe COPD patients in stable period. Int J Respir 2017;37:41-4.

22. Ni L. Effects of Yoga and Taiji on stable COPD. World Latest Medicine Information 2017;17:182-4.

23. Niu R, He R, Luo BL, et al. The effect of tai chi on chronic obstructive pulmonary disease: a pilot randomised study of lung function, exercise capacity and diaphragm strength. Heart Lung Circ 2014;23:347-52.

24. Pan Y, Wang ZX, Min J, et al. 24-form Tai Chi Quan combined with breathing exercise and western medicine for patients with stable obstructive pulmonary disease. Chin J Rehabil Med 2018;33:681-6.

25. Ren ZF, Zhang X, Hou GH, et al. Effects of Tai Chi Zen on exercise ability and quality of life in chronic obstructive pulmonary disease. Chin J Tradit Chin Med 2017;32:3507-10.
26. Wang YX, Mo JC, Cheng DH, et al. Effects of Taijiquan on quality of life and BODE Index in patients with chronic obstructive pulmonary disease. Chin J Rehabil Med 2014;29:745-7.

27. Yao YP. Effects of Tai Chi Chuan on chronic obstructive pulmonary disease. Chin J Rehabil Theory Pract 2004;10:59-60.

28. Zhang LH, Wu JJ, Wang ZC. Effects of 24-style Taijiquan combined with respiratory rehabilitation on lung function and quality of life in COPD. Acta Universitatis Traditionis Medicalis Sinensis Pharmacologiaeque Shanghai 2012;26:53-6.

29. Zhou Y, Wu L, Wang DX. The rehabilitative effects of Taijiquan training with east medical on middle-elderly COPD patients. Joural of Jilin Institute of Physical Education 2009;25:54-5.

30. Zhu S, Shi K, Yan J, et al. modified 6-form Tai Chi for patients with COPD. Complement Ther Med 2018;39:36-42.

31. Ng BH, Tsang HW, Ng BF, et al. Traditional Chinese exercises for pulmonary rehabilitation: evidence from a systematic review. J Cardiopulm Rehabil Prev 2014;34:367-77.

32. Ding M, Zhang W, Li K, et al. Effectiveness of t'ai chi and qigong on chronic obstructive pulmonary disease: a systematic review and meta-analysis. J Altern Complement Med 2014;20:79-86.

33. Yan JH, Guo YZ, Yao HM, et al. Effects of Tai Chi in patients with chronic obstructive pulmonary disease: preliminary evidence. PLoS One 2013;8:e61806.

34. Ngai SP, Jones AY, Tam WW. Tai Chi for chronic obstructive pulmonary disease (COPD). Cochrane Database Syst Rev- Intervention Version published: 07 June 2016. Available online: https://doi. org/10.1002/14651858.CD009953.pub2

35. Wayne PM, Berkowitz DL, Litrownik DE, et al. What do we really know about the safety of tai chi?: A systematic review of adverse event reports in randomized trials. Arch Phys Med Rehabil 2014;95:2470-83.

Cite this article as: $\mathrm{Liu} \mathrm{X}, \mathrm{Fu} \mathrm{C}, \mathrm{Hu} \mathrm{W}$, Hao S, Xie L, Wu X, Wang J, Liu Z, Lin Q, Li S. The effect of Tai Chi on the pulmonary rehabilitation of chronic obstructive pulmonary disease: a systematic review and meta-analysis. Ann Palliat Med 2021;10(4):3763-3782. doi: 10.21037/apm-20-940 